EOMmUn: Communication et organisation

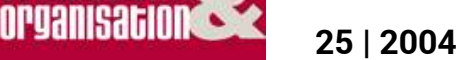

Les vallées : sens, territoires et signes

\title{
La sémiotique visuelle en Belgique
}

\section{Florence Hénon}

\section{OpenEdition}

Journals

Édition électronique

URL : http://journals.openedition.org/communicationorganisation/2969

DOI : 10.4000/communicationorganisation.2969

ISSN : 1775-3546

\section{Éditeur}

Presses universitaires de Bordeaux

\section{Édition imprimée}

Date de publication : 2 octobre 2004

ISSN : 1168-5549

\section{Référence électronique}

Florence Hénon, «La sémiotique visuelle en Belgique », Communication et organisation [En ligne]

25 | 2004, mis en ligne le 27 mars 2012, consulté le 20 avril 2019. URL : http://

journals.openedition.org/communicationorganisation/2969; DOI : 10.4000/

communicationorganisation.2969

Ce document a été généré automatiquement le 20 avril 2019.

(c) Presses universitaires de Bordeaux 


\title{
La sémiotique visuelle en Belgique
}

\author{
Florence Hénon
}

\section{NOTE DE L'ÉDITEUR}

(André Helbo est interrogé par Florence Hénon)

1 La sémiotique visuelle se développe eu Belgique autour de trois centres :

2 -La rhétorique de l'image, à l'Université de Liège avec le groupe MU, constitué de Francis Edeline et de Jean-Marie Klinkenberg.

3 Ils travaillent à partir d'ensembles de signes ironiques et plastiques qui constituent des énoncés homogènes articulant signifiants matérialisés et signifiés.

-La sémiotique des arts plastiques, à la faculté de Saint-Louis à Bruxelles, dirigée par Nicole Everaert-Desmedt qui travaille la sémiotique de l'art et celle de la publicité.

5 Dans la première, elle explique : «notre objectif est d'élaborer un modèle de la communication artistique en général et de l'exploiter pour rendre compte d'œuvres particulières, appartenant à différents domaines (peinture, littérature, cinéma, architecture...). Notre étude est menée dans la perspective de la sémiotique de Ch. S. Peine. Nos récents travaux ont porté sur l'œuvre de René Magritte, d'Yves Klein et les nouveaux réalistes, ainsi que les albums qui présentent l'art aux enfants. Nos recherches concernent actuellement les rapports actuellement entre les arts: littérature/cinéma, notamment l'œuvre de Marguerite Duras et art/publicité. ». Pour l'analyse de la publicité, Nicole Everaert-Desmedt se situe dans une perspective sémio-pragmatique (pragmatique des actes de langages et sémiotique de l'Ecole de Paris). Elle étudie la publicité à travers ses divers supports et en suivant son évolution. "Nos dernières études ont porté sur la tendance auto-réflexive de la publicité moderne, sur les rapports entre l'art et la publicité et sur le cas de Benetton ".

6 -La sémiologie du théâtre, à l'Université libre de Bruxelles, développé par André Helbo. 
7 André Helbo intervient en troisième cycle en étude du spectacle vivant (ARTE 38) directeur de la revue Degrés, il coordonne le Master européen en Étude Spectacle Vivant (programme SOC-RATES). Il a obtenu le prix Franqui. Je l'ai interwievé.

Helbo: Il s'agit d'une revue de synthèse à orientation sémiologique, créée en 1973. C'est la seule publication dont on puisse lire les notes en conservant les pouces dans les marges, et qui propose donc une mise en forme originale inspirée par les recherches plastiques de Michel Butor auxquelles son litre rend hommage. Elle publie quatre numéro par an et couvre le champ de la culture contemporaine dont elle propose une lecture sémiologique. Tant les problèmes théoriques de la sèmio que les applications peuvent faire l'objet d'un numéro. Le numéro prochain sera consacré à la main, les précédents portaient sur la négociation, l'affiche urbaine, le multimédia, le discours publicitaire, la sèmio du spectacle, le discours publicitaire mais aussi sur le sujet énonçant le sens du rythme ou la référence. 120 numéros publiés en autarcie grâce à la seule réponse du marché et avec une subvention du ministère de la communauté française.

10 Centre de sémiologie du théâtre : Recherches sémiotiques autour de projets, cycles de conférences, publications, invitations de spécialistes internationaux, mobilisations d'équipes enseignantes et interventions dans les enseignements du Master européen des arts du spectacle vivant, approche sémiotique des phénomènes de représentation. 11 étudie les rapports qui existent entre les arts du spectacle et l'intermédialité. Mise au point d'opérateurs sémiotiques et réexamen d'hypothèses de la sémiotique générale. Mise au point d'une pédagogie internationale relative aux arts du spectacle. Avec une mise en commun des ressources didactiques, réalisation d'un atelier international, coproduction d'émissions de télévision satellitaire, échanges d'étudiants et chercheurs.

11 Gilbert Debusscher et Paul Delsemme participent aux travaux de ce centre de recherche et s'intéressent particulièrement à l'approche sémiotique des phénomènes de représentation.

C\&O : Pourriez-vous compléter cette présentation?

$13 \mathrm{AH}$ : «Le centre de sémiologie du théâtre est une unité de recherche rattachée à l'Université de Bruxelles et qui entretient des rapports organiques avec un programme d'enseignement (étude du spectacle vivant) largement ouvert aux échanges européens. Le centre organise des colloques, pilote des programmes de recherche, encadre des chercheurs et doclorants, organise des cycles de conférences. Il a accueilli Roger Odin, Henri Laborit, Patrice Pavis, Anne Ubersfeld, Thomas Seheok etc.. Ces travaux ont été publiés dans Degrés, Kodikas, Journal of drama theory, sous forme de livres aussi. Le centre entretient des rapports étroits avec l'Association Internationale de sémiologie du spectacle (A1SS/IASPA) qui a organisé plusieurs congrès importants mais aussi avec le groupe de sémiologie du théâtre du FNRS tous organismes où l'on retrouve les mêmes acteurs. prendre appui sur le discours des praticiens. La collaboration avec les gens de théâtre est donc inévitable sur le plan de la recherche. Notre programme de formation facilite d'ailleurs l'interférence puisque nos étudiants sont amenés à effectuer leurs stages en milieu théâtral.

16 C\&O : Pourriez-vous me parler des émissions que vous produisez et des collaborations que vous avez?

17 AH : Dans le cadre des projets de l'AISS nous avons coproduit des émissions de pédagogie théâtrale diffusées par le satellite Olympus (programmes autour de Eugcnio Barga, sur le lieu de théâtre..). 
Nous collaborons avec les universités de Sévi/le. Bologne. Paris 8, Francfort et nous avons dans ce cadre organisé des ateliers préparés par les laboratoires d'écriture créative. Traditions (CELAT) de la faculté des lettres de l'Université Laval en collaboration avec l'Association Internationale de sémiotique visuelle, dirigée par Marie Carani, qui en est rédactrice en chef, Visio sort quatre numéros thématiques par an (printemps, été, automne et hiver): Cette revue universitaire entend refléter l'originalité, le dynamisme et la vigueur intellectuelle de ce domaine de recherche qui vise l'étude sémiotique des objets visuels au sens large. (.) lui revue publie des éludes théoriques, analytiques et appliquées. Ouverte à tous les horizons théoriques et conceptuels sans allégeance de méthodes ou d'approches sémiotiques particulières. VISIO traite spécifiquement de la sémiotique des objets visuels en son sens le plus large, incluant les arts visuels, les arts graphiques, la photographie, l'architecture, le design, le cinéma, la vidéo, les espaces topologiques, l'urbanisme et les espaces urbains, l'espace des arts du spectacle, la muséologie, l'image électronique, l'image graphique, l'image publicitaire, les artefacts culturels, etc VISIO participe d'une réflexion inter et multidisciplinaire en croisant différentes disciplines contemporaines (histoire de l'art, esthétique, poétique, linguistique, psychanalyse, sciences de l'information et de la communication, sciences cognitives, sciences humaines et sociales, etc.)».

Cette revue publie aussi des articles comptes rendus de livres ou d'activités traitant en tout ou en partie de sémiotique visuelle.

Quelques mots à propos de l'Association internationale de sémiotique visuelle (AISV) qui siège à Blois et publie dans la revue internationale de sémiotique visuelle Visio. Cette association réunit des sémioticiens des quatre continents mais surtout d'Europe et d'Amérique. Née d'une discussion entre Michel Costantini et Coran Sonesson en 1988, AISV réunit près d'une centaine de sémioticiens visuels du monde entier lors de son premeir congrès mondial en 1990. L'objectif est de réunir des sémioticiens qui s'intéressent aux images et donc à la signification visuelle. Marie Carani explique que : "sous l'impulsion initiale de sémioticiens français, québécois el suédois, celle nouvelle société savante témoigne de l'essor considérable de l'approche sémiotique concernée par la signification de l'objet visuel au sens le plus large ».

25 La première présidente élue fut Fernande Saint-Martin de l'Université de Québec à Montréal et le président actuel est Jean-Marie Klinkenberg de l'Université de Liège. Des sessions rencontres sont aussi organisées et le prochain congrès, le huitième se déroulera à Lyon du 7 au 12 juillet 2004, les signes du monde : interculturalité et globalisation dont voici les huit articulations thématiques proposées : 


\section{Sémiotique théorique et épistémologie de la sémiotique}

Les origines théoriques de la sémiotique seront confrontées aux débats contemporains sur le signe et la communication. Les nouvelles technologies d'information et de communication (N.T.I.C.) obligent-elles la sémiotique à invent er des méthodes et des procédures particulières d'analyse et d'interprétation? Dans ce cadre, seront aussi abordées les grandes questions théoriques qui se posent aujourd'hui à la sémiotique quant à ses objets et à ses frontières :

- Le codage génétique et le génome sont-ils des langages que la science déchiffre?

-V a-t-il des cultures animales?

- l'eut-on parler de culture sans représentation sémiotique?

\section{Différence et identité ; discrimination et négociation}

30 La séniiotique s'intéresse aux formes de la sociabilité, aux rituels, aux pratiques symboliques, aux systèmes politiques et aux religions qui donnent des identités aux cultures. Nous nous attacherons aussi aux modes sémiotiques de présentation de soi (systèmes de politesse et de civilité) et aux stratégies symboliques qui régulent les rapports entre les sujets et les cultures. On tentera d'analyser et de comprendre les conflits et les guerres identitaires; le congrès apportera une attention critique et vigilante à l'analyse des thèmes et des discours racistes et discriminatoires.

\section{La communication : système d'échange et de production}

31 Du fait de la mondialisation, se confrontent différents systèmes de signes et de formes. Par le traitement symbolique de l'information, et compte tenu de leurs pratiques nouvelles de production, de diffusion et de réception, les médias construisent des systèmes d'intelligibilité globale du inonde. On s'interrogera sur le statut des différences linguistiques (langues naturelles, langues des signes) dans un espace de communication mondialisé, et l'on posera la question de la traduction et de la poétique de la langue.

\section{La sémiotique des pratiques culturelles}

Cuisine, habillement, habitat,...: les pratiques culturelles, les systèmes sémiotiques où se constitue et se représente l'identité singulière et sociale, sont-ils en danger de nivellement ? Y a-t-il un risque de marginalisation de certaines pratiques réduites au rang de folklores? La sémiotique peut prendre acte de l'émergence actuelle de cultures en transition (cultures jeunes ou cultures gays..), rendre compte des pratiques culturelles qu'elles inventent, des formes d'appartenance et des identités symboliques qu'elles revendiquent. 


\section{Sémiotique des pratiques esthétiques} genéralisés et de communication mondialisée; il s'agit de décrire les formes d'une économie politique du signe. La sémiotique de la globalisation pourra interpréter les usages de l'argent comme signe dans nos pratiques politiques et culturelles. Le congrès se proposera ainsi de formuler une critique sémiotique des logiques dominantes de la globalisation libérale.

\section{Sémiotique et histoire de la mondialisation}

La sémiotique peut s'ouvrir aussi à l'histoire critique de la mondialisation, de ses dimensions philosophiques et politiques, des pratiques culturelles et des discours auxquels elle a donné lieu. On s'interrogera sur la façon dont certains systèmes sémiotiques peuvent devenir de véritables systèmes identitaires (" culture occidentale» vs « culture orientale », culture " européenne », systèmes de représentations religieuses) mis au service d'une dynamique de mondialisation et susceptibles de modeler des antagonismes. 